\title{
Are perceived neighbourhood problems associated with the likelihood of smoking?
}

\author{
A Ellaway, S Macintyre
}

MRC Social \& Public Health Sciences Unit, Glasgow, UK

Correspondence to: Dr A Ellaway, MRC Social \& Public Health Sciences Unit, 4 Lilybank Gardens, Glasgow G12 8RZ, UK; anne@sphsu.mrc.ac. uk

Accepted 8 February 2008

\section{ABSTRACT}

Objective: To explore associations between residents' perceptions of the local residential environment and the likelihood of their smoking.

Design: Using data $(n=2615)$ from the West of

Scotland Twenty-07 Study, separately by gender, crosssectional associations between respondents' perceptions of neighbourhood (perceived absence of goods, incivilities and physical environmental problems) and the likelihood of being a current smoker and the amount smoked were examined.

Results: Perceived neighbourhood problems are associated with the likelihood of smoking but mainly among those with the most negative view of the local neighbourhood. Perceptions of the provision of neighbourhood amenities seems to be more strongly associated with women's than men's smoking status, whereas the perceived quality of the local neighbourhood appears to be a better predictor of men's smoking. Conclusions: Efforts to reduce smoking levels among more deprived groups may need to pay more attention to the role of local environmental conditions in influencing smoking behaviour.

A number of studies have shown that where people live is associated with the likelihood of smoking, even after controlling for individual socioeconomic factors. ${ }^{1-10}$ Various explanations for this observation include local norms and culture, ${ }^{11} 12$ and smoking as a potential coping mechanism to mediate stresses, including those associated with living in an unpleasant or threatening residential environment. ${ }^{13} 14$

The degree to which people perceive their residential environment to be pleasant or otherwise has been shown to be associated with various health outcomes. ${ }^{15-20}$ We explore associations between residents' perceptions of the local residential environment and the likelihood of smoking. Few studies have examined this issue, with most previously published work relying on a fairly narrow range of neighbourhood perceptions. ${ }^{17} 2122$ Our data allow us to examine several dimensions of perceived neighbourhood conditions. We do this separately for men and women, as gender differences have been shown in the associations between health and the experience of place $e^{23-25}$ and the determinants of smoking. ${ }^{26-28}$

\section{METHODS}

\section{Study population}

This paper is freely available online under the BMJ Journals unlocked scheme, see http:// jech.bmj.com/info/unlocked.dtl
The analysis used a subset of data from the fourth sweep (conducted in 2001) of the West of Scotland Twenty-07 Study: Health in the Community. ${ }^{29}$ At this sweep 2661 respondents took part, 2615 of whom had complete data for the variables examined here. The survey respondents are broadly representative of the West of Scotland population.

\section{Sociodemographic measures}

The survey involves three cohorts: the mean age of each cohort when interviewed was 30 ( $n=824), 50$ $(n=967)$ and $68(n=824)$ year respectively; 1437 women and 1178 men.

Registrar General's occupation-based classification scheme $e^{30}$ using the last known occupation of the head of the respondent's household was used to determine social class.

\section{Perceived neighbourhood problems}

Respondents were asked about 16 types of socioenvironmental problems in their neighbourhood, and invited to reply using a three-point scale ("not a problem" score 1, "minor problem" score 2, "serious problem" score 3). Using factor analysis, three domains emerged from the 16 items: "incivilities" (litter, vandalism, burglaries, disturbance by children or youths, nuisance from dogs, assaults, discarded needles/syringes, people, reputation of the neighbourhood), "absence of goods" (lack of safe play areas for children, lack of recreation facilities, difficulties obtaining services) and "physical environmental problems" (speeding traffic, derelict/waste ground, uneven/dangerous pavements, smells and fumes). For each of these three domains, a score was constructed by summing responses to each item making up the domains. These scores were subsequently divided into quartiles, with those in the lowest quartile being the most positive and those in the highest quartile being the most negative about their local neighbourhood.

\section{Smoking status}

Respondents were asked about their smoking status, choosing from three categories: an exsmoker, never smoked or current smoker. Under a third (30.6\% men and 28\% women) in our sample were current smokers $(n=763)$, which is broadly similar to the Scottish population as a whole. ${ }^{31}$ Current smokers were asked about the number of cigarettes or cigars smoked per day; this ranged from 1 to 60 per day (mean 14.24, (SD) 9.6) among men, and 1-80 per day (mean 15.07 (SD) 9.2) among women.

\section{Analyses}

Statistical analyses were performed using SPSS V.12.0, undertaken separately for men and 
Table 1 Odds ratio (95\% Cl) for likelihood of being a current smoker*

\begin{tabular}{|c|c|c|c|c|}
\hline & \multicolumn{2}{|l|}{ Men } & \multicolumn{2}{|l|}{ Women } \\
\hline & OR (95\% CI) & p Value & OR (95\% CI) & p Value \\
\hline \multicolumn{5}{|l|}{ Absence of goods } \\
\hline 1 Lowest score $\dagger$ & 1 & & 1 & \\
\hline 2 & $0.79(0.55$ to 1.15$)$ & 0.219 & $0.91(0.65$ to 1.27$)$ & 0.583 \\
\hline 3 & $1.13(0.79$ to 1.61$)$ & 0.509 & 1.24 (0.88 to 1.72$)$ & 0.217 \\
\hline $\begin{array}{l}4 \text { Highest score } \\
\text { Incivilities }\end{array}$ & $1.51(1.06$ to 2.14$)$ & 0.021 & 1.64 (1.18 to 2.28 ) & 0.003 \\
\hline 1 Lowest score $\dagger$ & 1 & & 1 & \\
\hline 2 & $1.23(0.88$ to 1.73$)$ & 0.233 & $1.02(0.75$ to 1.39$)$ & 0.884 \\
\hline 3 & $1.27(0.87$ to 1.84$)$ & 0.213 & $1.18(0.84$ to 1.65$)$ & 0.332 \\
\hline 4 Highest score & 2.21 (1.53 to 3.20$)$ & 0.001 & 1.42 (1.01 to 2.03$)$ & 0.045 \\
\hline \multicolumn{5}{|c|}{$\begin{array}{l}\text { Physical environmental } \\
\text { problems }\end{array}$} \\
\hline 1 Lowest score $\dagger$ & 1 & & 1 & \\
\hline 2 & $1.06(0.75$ to 1.48$)$ & 0.755 & $1.11(0.80$ to 1.52$)$ & 0.536 \\
\hline 3 & $1.14(0.78$ to 1.65$)$ & 0.498 & $1.04(0.74$ to 1.48$)$ & 0.807 \\
\hline 4 Highest score & 1.78 (1.25 to 2.53$)$ & 0.001 & 1.55 (1.12 to 2.15$)$ & 0.008 \\
\hline
\end{tabular}

${ }^{*}$ Regression models based on age, social class and perceived neighbourhood problems entered simultaneously (separate models for absence of goods, incivilities and physical environmental problems).

$\uparrow$ Reference category.

women, as interactions by gender were found for perceived absence of goods $(p<0.001$, CI 1.006 to 1.088); perceived incivilities $(p<0.04$, CI 1.002 to 1.090$)$ and physical environmental problems $(p<0.052$, CI 1.000 to 1.081). Logistic regression was used to calculate the odds ratio (95\% CI) for the likelihood of being a current smoker (as a binary variable: current smokers compared with non-current (former and never)), with age, social class and perceived neighbourhood problems entered simultaneously (separate models were constructed for absence of goods, incivilities and physical problems) with the lowest quartile (the group most positive about their local neighbourhood) being the reference category. The $p$ value $<0.05$ was used as the cut-off for statistical significance.

Differences in the reported number of cigarettes smoked per day were also examined, using general liner modelling and means (adjusted for cohort and social class) were calculated.

\section{RESULTS}

For each of our three domains of perceived neighbourhood problems, the likelihood of being a current smoker increased with rising levels of perceived problems (with the exception of perceived physical environmental problems and likelihood of smoking among women) (table 1). However, this was statistically significant only when comparing those with the highest quartiles of perceived problems with the lowest quartile. Gender differences were observed in the strength of those relationships, with perceived absence of goods being more important for women and perceived incivilities and physical environmental problems being more important for men.

Only one domain, absence of goods, was associated with the number of cigarettes/cigars smoked in both men and women (table 2), although among men the amount smoked was similar for those with the most negative and the most positive views. Among women, those with the most negative view smoked, on average, more than three cigarettes per day more than those female smokers with the most positive view.
Table 2 Mean number* of cigarettes/cigars smoked per day†

\begin{tabular}{|c|c|c|c|c|}
\hline & \multicolumn{2}{|l|}{ Men } & \multicolumn{2}{|l|}{ Women } \\
\hline & Mean & p Value: (F) & Mean & p Valuet (F) \\
\hline Absence of goods & \multicolumn{3}{|c|}{$0.024(F=3.18)$} & $0.030(\mathrm{~F}=3.02)$ \\
\hline 1 Lowest score & $14.48(1.01)$ & & $12.38(0.93)$ & \\
\hline 2 & $10.68(1.32)$ & & $12.27(1.14)$ & \\
\hline 3 & $12.08(1.19)$ & & $14.59(1.02)$ & \\
\hline 4 Highest score & $14.67(1.07)$ & & $15.54(0.93)$ & \\
\hline Incivilities & \multicolumn{3}{|c|}{$0.67(F=0.52)$} & $0.47(F=0.85)$ \\
\hline 1 Lowest score & $14.29(1.12)$ & & $12.92(0.93)$ & \\
\hline 2 & $12.59(1.10)$ & & $14.36(0.94)$ & \\
\hline 3 & $13.85(1.30)$ & & $13.35(1.07)$ & \\
\hline 4 Highest score & $13.29(1.08)$ & & $14.82(1.10)$ & \\
\hline $\begin{array}{l}\text { Physical } \\
\text { environmental } \\
\text { problems }\end{array}$ & \multicolumn{3}{|c|}{$0.32(F=1.18)$} & $0.35(F=1.10)$ \\
\hline 1 Lowest score & $14.53(1.04)$ & & $13.68(0.92)$ & \\
\hline 2 & $11.98(1.14)$ & & $12.88(1.01)$ & \\
\hline 3 & $13.09(1.28)$ & & $13.21(1.18)$ & \\
\hline 4 Highest score & $13.74(1.11)$ & & $15.11(0.96)$ & \\
\hline
\end{tabular}

${ }^{*}$ Adjusted for cohort and social class.

†Current smokers only.

tp Values related to model as a whole.

\section{DISCUSSION}

We have found that perceived neighbourhoods problems are associated with the likelihood of smoking but mainly among those with the most negative view of the local neighbourhood. There are several potential explanations for our findings; for example, it may be that areas which have the poorest environments are particularly influential in inducing smoking behaviour as a response to the stress of living there; it may be that social norms with regard to smoking are operating more strongly in these neighbourhoods; or it may be that cigarettes are more readily available in the poorest neighbourhoods either through more shops selling tobacco products or that contraband products are more easily and cheaply available. ${ }^{32}$ Because these are cross-sectional data, we cannot rule out the possibility that both smoking and negative views about the environment are influenced by a fourth factor (personality, mental health or mood), or that smokers are selected in some way into less attractive neighbourhoods.

Perceptions of the availability of neighbourhood amenities seems to be more strongly associated with women's than men's smoking status, whereas the quality of the local neighbourhood appears a better predictor of men's smoking. It may be as women tend to be the main carers for children ${ }^{24}{ }^{33}$ they are more sensitised to particular aspects of their local neighbourhood, such as the availability of safe places to play. The gendered experience and consequences of place for health have only begun to be noted in a few other studies, ${ }^{21}{ }^{23} 24$ suggesting a need for further research.

In conclusion, smoking is a major public health concern and a major contributor to socioeconomic inequalities in health. ${ }^{34} 35$ People who smoke in deprived areas are less likely to give up smoking than their more affluent counterparts ${ }^{36}$ and efforts which target individuals have had a limited effect among more deprived groups. ${ }^{37-39}$ Our results suggest that closer attention may need to be paid to the role of local environmental conditions in influencing smoking behaviour.

Competing interests: None declared. 


\section{What is already known on this subject}

A number of studies have shown that area of residence is associated with the likelihood of smoking, although the precise mechanisms are not well understood as yet.

- Some recent studies have found that perceptions of the local environment (as pleasant or otherwise) may contribute to smoking behaviour.

\section{What this study adds}

- This study found that residents with very negative views of their local neighbourhood are more likely to smoke, even after taking individual characteristics into account.

- Women's smoking status is associated with a perceived lack of local amenities (eg safe play areas for children), whereas the quality of the local neighbourhood (eg presence of litter and graffiti) appears to be a better predictor of men's smoking.

\section{Policy implication}

Closer attention may need to be paid to the role of local environmental conditions in potentially influencing smoking behaviour.

\section{REFERENCES}

1. Chaix B, Guilbert P, Chauvin P. A multilevel analysis of tobacco use and tobacco consumption levels in France - Are there any combination risk groups? Eur J Public Health 2004;14:186-90.

2. Datta GD, Subramanian SV, Colditz GA, et al. Individual, neighborhood, and statelevel predictors of smoking among US Black women: A multilevel analysis. Soc Sci Med 2006;6:1034-44.

3. Davey Smith G, Hart C, Watt G, et al. Individual social class, area-based deprivation, cardiovascular disease risk factors, and mortality: the Renfrew and Paisley study. J Epidemiol Community Health 1998;5:399-05

4. Duncan C, Jones K, Moon G. Smoking and deprivation: Are there neighbourhood effects? Soc Sci Med 1999;4:497-505.

5. Ellaway A, Macintyre S. Does where you live predict health related behaviours? A case study in Glasgow. Health Bull 1996;54:443-6.

6. Reijneveld SA. The impact of individual and area characteristics on urban socioeconomic differences in health and smoking. Int J Epidemiol 1998;27:33-40.

7. Ross CE. Walking, exercising, and smoking: does neighborhood matter? Soc Sci Med 2000;51:265-74.

8. Shohaimi S, Luben R, Wareham N, et al. Residential area deprivation predicts smoking habit independently of individual educational level and occupational social class. A cross sectional study in the Norfolk cohort of the European Investigation into Cancer (EPIC-Norfolk). J Epidemiol Community Health 2003;57:270-276.

9. Sundquist J, Malmstrom M, Johansson S. Cardiovascular risk factors and the neighbourhood environment: a multilevel analysis. Int J Epidemiol 1999;28:841-5.

10. Tseng M, Yeatts K, Millikan R, et al. Area-level characteristics and smoking in women. Am J Public Health 2001;9:1847-50.
11. Curry SJ, Wagner EH, Cheadle A, et al. Assessment of community-level influences on individuals attitudes about cigarette-smoking, alcohol-use, and consumption of dietary-fat. Am J Prev Med 1993;9:78-84.

12. Stead M, MacAskill S, MacKintosh A-M, et al. "It's as if you're locked in": Qualitative explanations for area effects on smoking in disadvantaged communities. Health Place 2001; 7:333-43.

13. Ellaway A, Macintyre S, Fairley A. Mums on Prozac, kids on inhalers: the need for research on the potential for improving health through housing interventions. Health Bull 2000;58:336-9.

14. Diez Roux AV, Merkin SS, Hannan P, et al. Area characteristics, individual-leve socioeconomic indicators, and smoking in young adults - The Coronary Artery Disease Risk Development in Young Adults Study. Am J Epidemiol 2003;157:315-26.

15. Sooman A, Macintyre S. Health and perceptions of the local environment in socially contrasting neighbourhoods in Glasgow. Health Place 1995;1:15-26.

16. Ellaway A, Macintyre S, Kearns A. Perceptions of place and health in socially contrasting neighbourhoods. Urban Stud 2001;38:2299-316.

17. Steptoe A, Feldman PJ. Neighborhood problems as sources of chronic stress: Development of a measure of neighborhood problems, and associations with socioeconomic status and health. An Behav Med 2001;23:177-85.

18. Wilson K, Elliot S, Law M, et al. Linking perceptions of neighbourhood to health in Hamilton, Canada. J Epidemiol Community Health 2004;58:1928.

19. Yen I, Yelin E, Katz P, et al. Perceived neighborhood problems and quality of life, physical functioning and depressive symptoms among adults with asthma. Public Health 2006;96:873-79

20. Bowling A, Barber J, Morris R, et al. Do perceptions of neighbourhood environment influence health? Baseline findings from a British survey of aging. J Epidemiol Community Health 2006;60:476-83.

21. Miles R. Neighborhood disorder and smoking: Findings of a European urban survey. Soc Sci Med 2006;63:2464-75.

22. Van Lenthe F, Mackenbach J. Neighbourhood and individual socio-economic inequalities in smoking: the role of physical neighbourhood stressors. J Epidemiol Community Health 2006;60:699-705.

23. Molinari C, Hendryx M. The relationship of community quality to the health of men and women. Soc Sci Med 1998;47:111-320.

24. Ellaway A, Macintyre S. Women in their place: gender and perceptions of neighbourhoods in the West of Scotland. In: Dyck I, Davis Lewis N, McLafferty S, eds. Geographies of Women's Health. London: Routledge, 2001.

25. Stafford M, Cummins S, Macintyre S, et al. Gender differences in the associations between health and neighbourhood environment. Soc Sci Med 2005;60:1681-92.

26. Flay BR, Hu FB, Richardson J. Psychosocial predictors of different stages of cigarette smoking among high school students. Prev Med 1998;27:A9-A18.

27. van den Bree MBM, Whitmer MD, Pickworth WB. Predictors of smoking development in a population-based sample of adolescents: A prospective study. J Adolesc Health 2004;35:172-181.

28. Leatherdale ST, Manske S, Kroeker C. Sex differences in how older students influence younger student smoking behaviour. Addict Behav 2006;31:1308-18.

29. Macintyre S, Annandale E, Ecob R, et al. The West of Scotland Twenty-07 Study: health in the community. In: Martin C, McQueen D, eds. Readings for a new public health. Edinburgh: Edinburgh University Press, 1989

30. OPCS. General Household Survey. London: HMSO, 1992.

31. Scottish Executive. Scottish Health Survey 2003 results. Edinburgh: Scottish Executive, 2005.

32. Wiltshire S, Bancroft A, Amos A, et al. "They're doing people a service" - qualitative study of smoking, smuggling and social deprivation. BMJ 2001;323:203-7.

33. Kavanagh AM, Bentley R, Turrell G, et al. Does gender modify associations between self rated health and the social and economic characteristics of local environments? J Epidemiol Community Health 2006;60:490-5.

34. Department of Health. Smoking kills: a white paper on tobacco. London: HMSO, 1998.

35. Scottish Executive. Our National Health - A plan for action, a plan for change. Action Summary. Edinburgh: HMSO, 2000.

36. Giskes K, Van Lenthe F, Turrell G, et al. Smokers living in deprived areas are less likely to quit: a longitudinal follow-up. Tob Control 2006;15:485-8.

37. Ferguson J, Bauld L, Chesterman J, et al. The English smoking treatment services; one year outcome. Addiction 2005;100:59-69.

38. Graham H, Inskip H, Francis B, et al. Pathways of disadvantage and smoking careers: evidence and policy implications. J Epidemiol Community Health 2006;60(Suppl II):7-12.

39. Judge K, Bauld L, Chesterman J, et al. The English smoking treatment services; short term outcomes. Addiction 2005;100:46-58. 